\title{
Retraction Note to: Mountain air pollution evaluation and urban public art based on data mining
}

\author{
Jun Zhang ${ }^{1} \cdot$ Kele Zhang ${ }^{2}$ \\ Published online: 18 November 2021 \\ (c) Saudi Society for Geosciences 2021
}

Retraction Note to: Arabian Journal of Geosciences (2021) 14: 1549 https://doi.org/10.1007/s12517-021-07946-y

The Editor-in-Chief and the Publisher have retracted this article because the content of this article is nonsensical. The peer review process was not carried out in accordance with the Publisher's peer review policy. Author Kele Zhang has not responded to correspondence regarding this retraction. The Publisher has not been able to obtain a current email address for author Jun Zhang.

The original article can be found online at https://doi.org/10.1007/ s12517-021-07946-y.

Kele Zhang

moonlight231023@126.com

1 School of Design, South China University of Technology, Guangzhou 510006, Guangdong, China

2 School of Art and Design, Guangdong University of Finance \& Economics, Guangzhou 510320, China 